\title{
Late left ventricular rupture as a complication of NeoChord implantation for mitral valve repair
}

Samer Kassem, MD, PhD, ${ }^{\mathrm{a}}$ Gabriella Ricciardi, MD, ${ }^{\mathrm{a}}$ Luca Salvi, $\mathrm{MD},{ }^{\mathrm{b}}$ and Marina Alimento, $\mathrm{MD},{ }^{\mathrm{c}}$ Milan, Italy

\footnotetext{
From the Departments of ${ }^{\mathrm{a}}$ Cardiovascular Surgery and ${ }^{\mathrm{b}}$ Anesthesia and Intensive Care Unit, and ${ }^{\mathrm{c}}$ Institute of Cardiology, Centro Cardiologico Monzino, IRCCS, Milan, Italy.

No funding was provided for this work.

Disclosures: Authors have nothing to disclose with regard to commercial support.

Received for publication Dec 7, 2017; revisions received Jan 24, 2018; accepted for publication March 1, 2018; available ahead of print April 11, 2018

Address for reprints: Samer Kassem, MD, PhD, Centro Cardiologico Monzino, Via Parea, 4, Milan 20138, Italy (E-mail: skassem@ccfm.it).

J Thorac Cardiovasc Surg 2018;156:e1-4

$0022-5223 / \$ 36.00$

Copyright (c) 2018 by The American Association for Thoracic Surgery

https://doi.org/10.1016/j.jtcvs.2018.03.006
}

- Video clip is available online.

These days, mitral valve repair (MVRep) is recognized as the criterion standard treatment for patients with mitral regurgitation (MR). Nontraditional procedures for MVRep have been recently developed, such as transapical off-pump MVRep with neochordal implantation. The NeoChord DS1000 (NeoChord, Inc, St Louis Park, Minn) is the first device approved to perform this type of surgery. ${ }^{1,2}$

Rupture of the left ventricle (LV) after MVR and MVRep is an infrequent but highly lethal complication that carries significant mortality. ${ }^{3-7}$ Many techniques have been proposed to reduce its dangerous incidence, such as posterior leaflet and chordae tendineae preservation, ${ }^{8}$ furthermore preserving LV geometry.

Rupture of the LV after MVRep with NeoChord device artificial chordae tendineae implantation is rarely described in the current literature. We present a case of late rupture of the LV after MVR performed in response to the failure of transapical NeoChord device artificial chordal implantation.

\section{CLINICAL SUMMARY}

A 71-year-old woman was referred to us with severe MR. Eight months previously, she had been treated for MR with chordal rupture through a minimally invasive approach because of important chronic obstructive pulmonary disease, renal impairment, and severe annular calcification (evaluated by transthoracic echocardiography). In the MVRep procedure, neochords were positioned with the NeoChord DS1000 system (Video 1). The procedure was performed by an expert surgeon with the collaboration of a lead surgeon (proctor). The 6-month follow-up

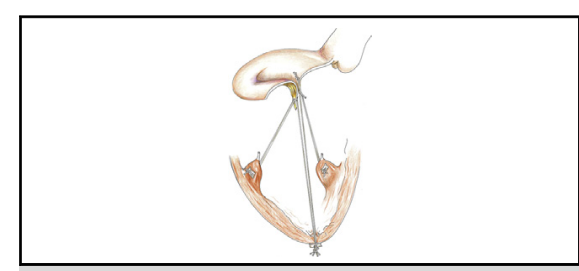

GORE-TEX artificial chordae tendineae and NeoChord implants.

Central Message
Complications are just part of the route to
developing a new surgical technique. Exhaus-
tive knowledge of the procedure, moreover, is
required to improve its reliability.

See Editorial Commentary page e5.

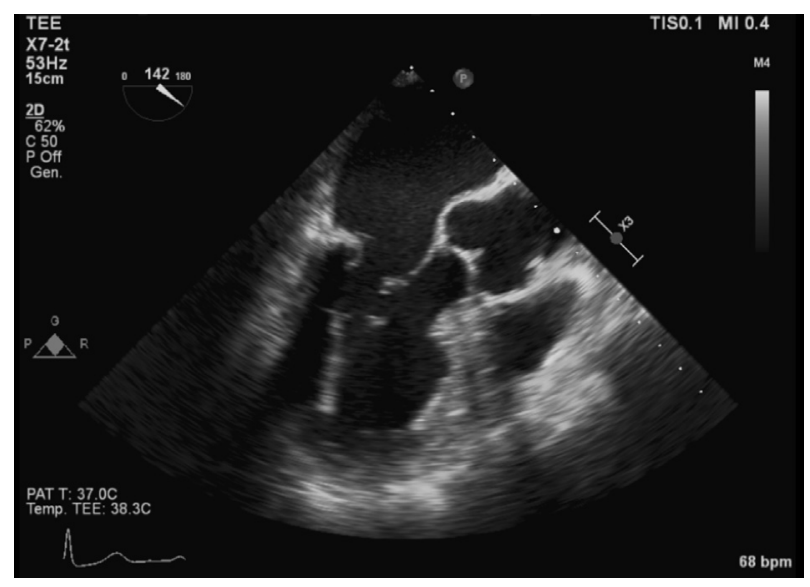

VIDEO 1. Intraoperative transesophageal echocardiography after neochordal implantation with the NeoChord DS1000 (NeoChord, Inc, St Louis Park, Minn). The video shows the apical position of the neochord attachment. Intraoperative 2- and 3-dimensional transesophageal echocardiographic imaging was used to navigate the NeoChord DS1000 device to the flailing segment of the posterior mitral valve leaflet. When the number of neochords needed to correct the regurgitation had been achieved, they were tensioned simultaneously under direct echocardiographic guidance to an optimal length to obtain adequate mitral valve competence. Video available at: https://www.jtcvs.org/ article/S0022-5223(18)30696-2/fulltext. 


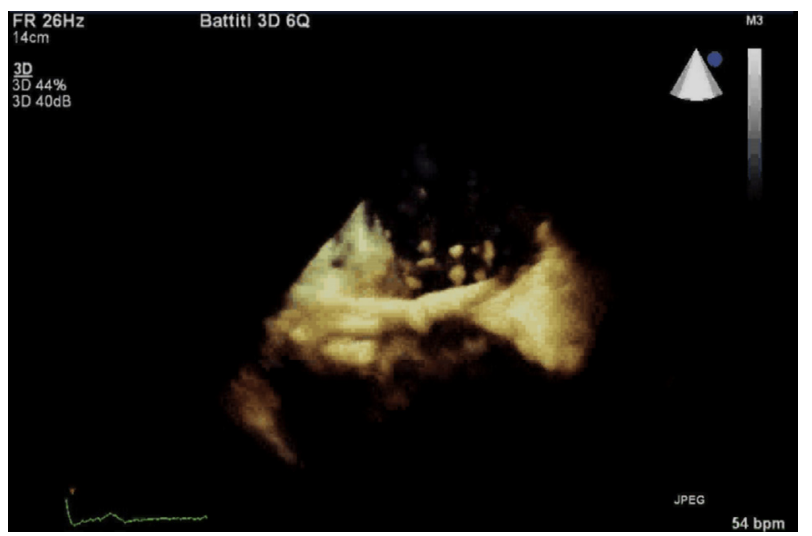

VIDEO 2. Intraoperative transesophageal echocardiography after cardiopulmonary bypass showing a good result of the mitral valve replacement. Video available at: https://www.jtcvs.org/article/S0022-5223(18)30696-2/ fulltext.

transthoracic echocardiography demonstrated detached neochords everting in the left atrium, conditioning severe MR (Video 2). An attempt was made to repair the native valve, but moderate MR persisted. A standard 29-mm Carpentier-Edwards PERIMOUNT Magna Ease bioprosthesis (Edwards Lifesciences Corporation, Irvine Calif) was therefore implanted, with a good result (Video $3)$. The postoperative course was uneventful until postoperative day 6 , when the patient began to report acute chest pain. An urgent coronary angiogram depicted a contrast liquid stasis near the LV apex with the involvement of distal right coronary artery (Figure 1). Transthoracic and transesophageal echocardiography showed severe LV dyskinesia of the apex and the distal lateral wall (Video 4). Computed tomographic scan was urgently performed (Figure 2). The patient was immediately moved to the operating room, but surgery could not be performed

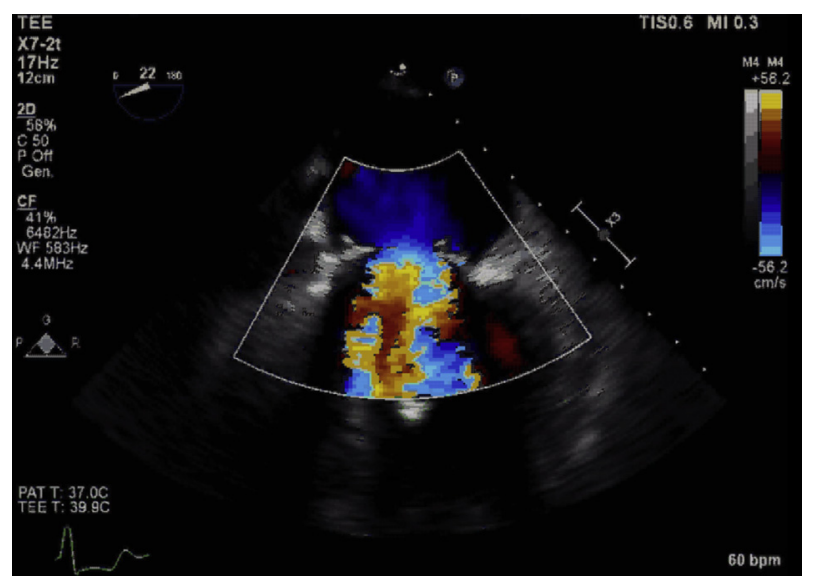

VIDEO 3. Transesophageal echocardiography showing the presence of severe left ventricular dysfunction, involving the apex and the distal lateral wall. Video available at: https://www.jtcvs.org/article/S0022-5223(18) 30696-2/fulltext. because of the rapid evolution of cardiac tamponade, followed in few minutes by the death of the patient.

\section{DISCUSSION}

Posterior ventricular rupture is a rare complication after MVR. It can be categorized into 3 types, ${ }^{7,9}$ according to the location: at atrioventricular groove, at the LV posterior wall (at the base of the papillary muscle [PM]), or on the posterior LV wall (between the base of the PM and the atrioventricular groove). Depending on the time of tear presentation, rupture of the LV has been also categorized as immediate, delayed, or chronic. Immediate or early tears occur in the operating room, which ensures early resuscitation and thus better survival. Delayed tears present hours to days after the procedure. Clinically, these forms present with severe hypotension and shock. Chronic tears occur days to years after MVR and share clinical and morphologic aspects with LV pseudoaneurysm. ${ }^{10}$

Factors resulting in a fragile myocardium clubbed with operative trauma appear to precipitate an incipient rupture of the LV. ${ }^{7}$ In the advanced myocardial hematoma process, detecting the initial point of infiltration may be hard.

In the case presented here, the rupture of the LV started from an intramyocardial hematoma located at the ventricular apex. Logically, we could suspect the presence of a fragile area corresponding to the apical site of the detachment of the neochords. The early coronary angiogram also demonstrated a contrast liquid stasis near the LV apex, confirming that the process of hematoma formation had begun at the apical location. We believe that MVR with a functioning prosthesis had forced the LV to work at full bore and then increased the shear stress on the myocardium. This acquired stress may have speeded the progression of myocardial hematoma and led to epicardial rupture.

Several technical aspects of the procedure of artificial chordal implantation with the NeoChord device have been standardized, including the ventricular access site location and the neochord tensioning protocol. In line with our hypothesis, Jensen and colleagues ${ }^{11}$ have demonstrated that the peak increase in tension, which reflects the tension fluctuations in the neochords, is $40 \%$ greater in the artificial chordae fixed on the LV apex than in those fixed on the PM.

Moreover, although the localization of rupture of the LV after MVR involves the areas between the base of the PM and the atrioventricular groove, the rupture located between the base of PM and the apex can be categorized as a complication of new technologies of MVRep, such as the NeoChord device artificial chordal implantation, which relies on the fixation of the artificial chordae tendineae on the LV apex.

We believe that the possibility of failure of transapical off-pump MVRep with NeoChord device artificial chordal implantation and its possible complications has to be carefully evaluated when deciding to perform this 


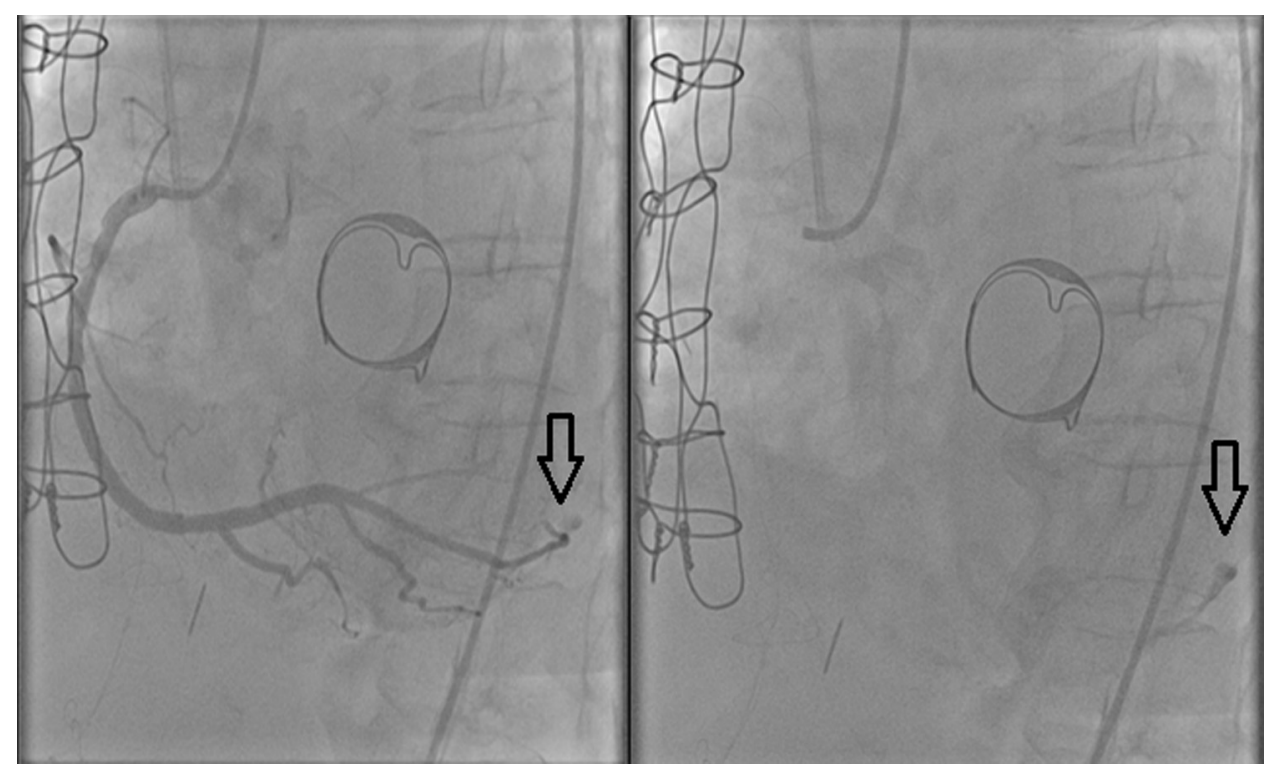

FIGURE 1. The urgent and early coronary angiography depicted a contrast liquid stasis near the left ventricular apex with the involvement of distal right coronary artery. The 2 panels represent different moments of the same urgent angiography: The early and late contrast liquid stasis in the right coronary artery. The arrows point to the contrast liquid stasis at the level of the left ventricular apex.

procedure. If the detachment of the neochords occurs at the mitral leaflet site, the repair of the valve can be carried out as for simple chordal rupture in common MV regurgitation. In the case of a detachment from the apex site, however, surgeons must concern themselves with myocardial fragility. Magnetic resonance imaging could help to evaluate the LV, taking into consideration the need to approach the case as an apical pseudoaneurysm before performing MVR.

In conclusion, we wish to focus attention on the proper indications for the new technologies of MVRep. It might be considered appropriate only in patients who cannot stand traditional surgery. This critical patient population should

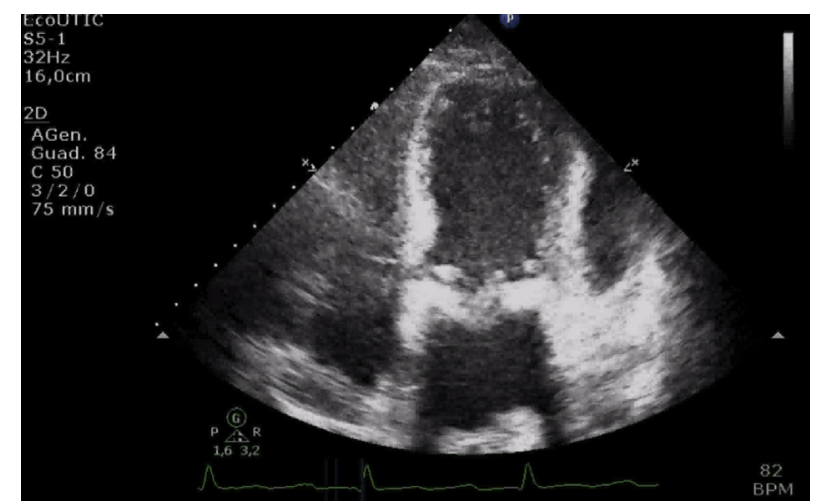

VIDEO 4. Transesophageal echocardiography showing severe left ventricular dyskinesia of the apex and the distal lateral wall. Video available at: https://www.jtcvs.org/article/S0022-5223(18)30696-2/fulltext. be treated only by the very skilled and faster surgeons of a team, with the purpose of reducing the time of cardiopulmonary bypass and cardiac arrest.

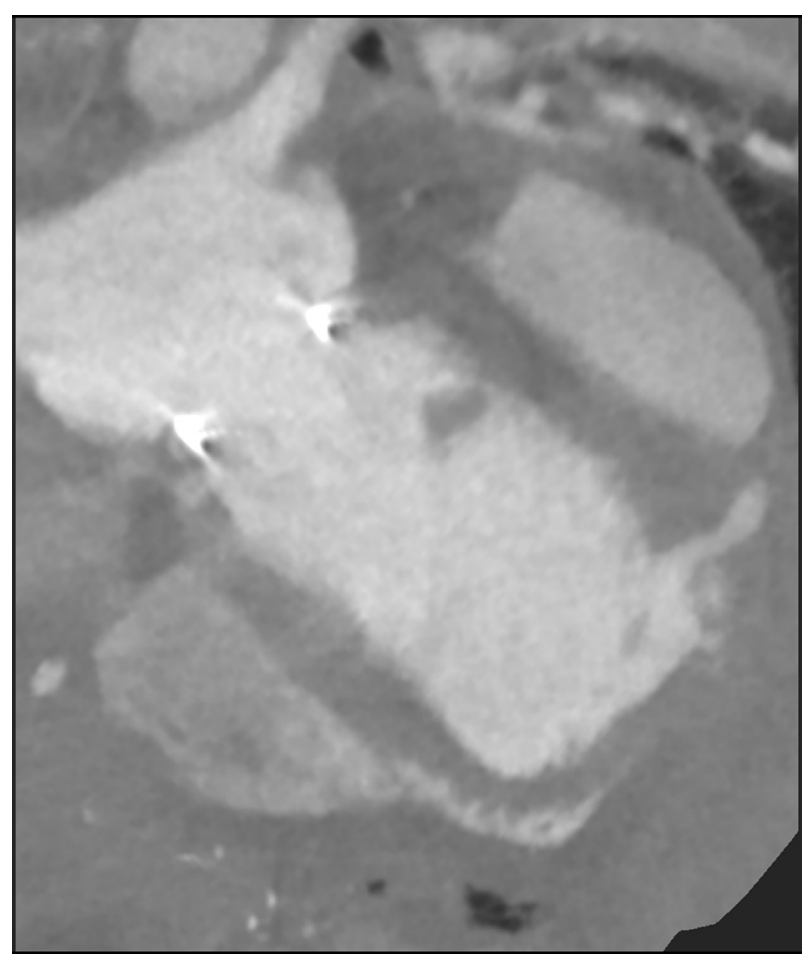

FIGURE 2. An urgent CT scan confirmed the diagnosis of ventricular rupture with an intramural hematoma on the medial and the inferior wall of the LV and the presence of the perforation site beside the LV apex. 
Another concern that rises up from our experience is that the NeoChord device artificial chordal implantation procedure does not respect the physiologic relationship between the MV and the LV. We therefore advocate carrying on with traditional techniques whenever possible, thus preserving this important relationship.

\section{References}

1. Gammie JS, Wilson P, Bartus K, Gackowski A, Hung J, D’Ambra MN, et al Transapical beating-heart mitral valve repair with an expanded polytetrafluoroethylene cordal implantation device: initial clinical experience. Circulation. 2016;134:189-97.

2. Colli A, Zucchetta F, Torregrossa G, Manzan E, Bizzotto E, Besola L, et al. Transapical off-pump mitral valve repair with neochord implantation (TOPMINI): step-by-step guide. Ann Cardiothorac Surg. 2015;4:295-7.

3. Spencer FC, Galloway AC, Colvin SB. A clinical evaluation of the hypothesis that rupture of the left ventricle following mitral valve replacement can be prevented by preservation of the chordae of the mural leaflet. Ann Surg. 1985; 202:673-80.
4. Schuetz A, Schulze C, Wildhirt SM. Off-pump epicardial tissue sealing- a novel method for atrioventricular disruption complicating mitral valve procedures. Ann Thorac Surg. 2004;78:569-73; discussion 573-4.

5. Wei J, Wu C, Hong G, Tung DY, Chang CY, Chuang YC. Autotransplantation of heart for repair of left ventricular rupture after mitral valve replacement. Transplant Proc. 2001;33:3553-4.

6. Izzat MB, Smith GH. Rupture of left ventricle after mitral valve repair: case report and new technique of repair. Br Heart J. 1993;69:366-7.

7. Deniz H, Sokullu O, Sanioglu S, Sargin M, Ozay B, Ayoglu U, et al. Risk factors for posterior ventricular rupture after mitral valve replacement: results of 2560 patients. Eur J Cardiothorac Surg. 2008;34:780-4.

8. Miller DW Jr, Johnson DD, Ivey TD. Does preservation of the posterior chordae tendineae enhance survival during mitral valve replacement? Ann Thorac Surg. 1979;28:22-7

9. Bisoyi S, Mohanty J, Mohapatra R, Nayak D. Left ventricular rupture postmitral valve replacement: surviving a catastrophe. Ann Card Anaesth. 2015;18:87-90.

10. Zhang HJ, Ma WG, Xu JP, Hu SS, Zhu XD. Left ventricular rupture after mitral valve replacement: a report of 13 cases. Asian Cardiovasc Thorac Ann. 2006;14: 26-9.

11. Jensen H, Jensen MO, Waziri F, Honge JL, Sloth E, Fenger-Gron M, et al. Transapical neochord implantation: is tension of artificial chordae tendineae dependent on the insertion site? J Thorac Cardiovasc Surg. 2014;148:138-43. 